\title{
Berberine Influences the Survival of Fat Grafting by Inhibiting Autophagy and Apoptosis of Human Adipose Derived Mesenchymal Stem Cells
}

\author{
Hao Pang \\ Yongting Zhou \\ Jie Wang \\ $\mathrm{Hao} \mathrm{Wu}$ \\ Xueyi Liu \\ Feng Gao \\ Zhibo Xiao
}

Department of Plastic Surgery, The Second Affiliated Hospital of Harbin Medical University, Harbin, Heilongjiang, I50086, People's Republic of China
Correspondence: Zhibo Xiao Department of Plastic Surgery, The Second Affiliated Hospital of Harbin Medical University, No. 246 Xuefu Avenue, Harbin, Heilongjiang, 150086, People's Republic of China

Email xiaozhibodoctor@I26.com
Objective: Human adipose-derived mesenchymal stem cells (ADSCs) have the potential to be applied to solid organ treatments. However, tissue regeneration is limited by the death of transplanted cells. Ischemia is the main cause of the poor outcome. This study aimed to investigate the effect of berberine (BBR) on ADSCs after fat grafting.

Methods: The antioxidant BBR on apoptosis and autophagy of ADSCs in vitro ischemia model was induced by hypoxia and serum deprivation (HY/SD). The autophagy promoter rapamycin and autophagy inhibitor 3-MA were incubated separately to investigate the crosstalk between autophagy and apoptosis. Pathway inhibitors further verified whether the autophagy and apoptosis were regulated by AMPK/mTor signaling pathway. Fat survival, fibrosis, level of inflammatory cell infiltration, and the effect of angiogenesis after BBR treatment were observed in vivo.

Results: BBR could reduce ROS production and reverse the decreasing cell survival rate. HY/SD would induce apoptosis and autophagy in ADSCs, and BBR could alleviate these processes. After interfering with the level of autophagy, we also proved that apoptosis was regulated by autophagy and changed accordingly. The results also indicated that BBR could protect against autophagy and apoptosis of ADSCs through AMPK/mTor pathway. The treated human-derived adipose tissue was transplanted into $\mathrm{BALB} / \mathrm{c}$ nude mice, and with the intervention of BBR, the fat grafting had a higher survival rate, lower inflammatory cell infiltration and fibrosis level.

Conclusion: Our present study revealed that BBR was a promising anti-autophagy and apoptosis agent for improving the survival rate of ADSCs during cell transplantation.

Keywords: adipose derived mesenchymal stem cells, berberine, autophagy, apoptosis, fat grafting

\section{Introduction}

Mesenchymal stem cell (MSC) is one of the most promising progenitor cells, due to its biological diversity, including the characteristic ability for proliferation, differentiation, and self-renewal and can be transplanted in large quantities, which have broad application prospects. ${ }^{1,2}$ MSCs provide support for wound healing and regeneration of damaged tissues or organs, indicating that MSCs have the ability to promote differentiation and activate endothelial cells. MSCs could be isolated from different systems, including adipose tissue. Autologous fat has been widely used in plastic surgery from its rich sources, convenient access and nonimmunogenicity. ${ }^{3}$ However, due to the low survival rate of adipocytes, fat grafting 
does not always achieve the expected effect, and tissue microenvironment ischemia is the major sticking point. ${ }^{4}$ Therefore, it is an urgent issue to improve the survival rate of adipocytes in the ischemic transplant position.

Research has confirmed that multiple elements, including apoptosis and autophagy, would lead to ADSCs death in an adverse environment of transplantation location. ${ }^{5}$ The processes of apoptosis and autophagy are regulated by intrinsic genes, which control cell fate and play vital roles in ontogeny and various diseases. ${ }^{6}$ Previous studies have shown that although the regulatory mechanisms between apoptosis and autophagy are different, some factors would regulate both. ${ }^{7}$ Under conditions of starvation and nutrient deficiency, autophagy is activated to generate metabolic intermediates to maintain ATP production and regulated by a variety of metabolites, including the ATP/ADP ratio and acetyl-CoA. Nutritional deficiency will affect the activity of various acetyltransferases. ${ }^{8}$ AMPK is a kinase allosterically activated by AMP and plays a vital role in the regulation of autophagy. Energy levels in the form of ADP/ATP ratios trigger autophagy by activating AMPK. ${ }^{9}$ It has recently been proposed that in addition to maintaining cell ATP homeostasis and regulating metabolism, AMPK is also involved in the regulation of cell apoptosis or survival under stress conditions. ${ }^{10}$ However, whether it is a pro-apoptotic molecule or a prosurvival molecule is currently unclear. In fact, the internal environment, duration of signal cascade activation and cell type determine the role of AMPK and complicate its regulation of apoptosis among which AMPK-mTorc1 pathway is one of the most important metabolic checkpoints controlling cell death. ${ }^{11}$ In this sense, the activation of mTorc1 by AMPK could limit protein translation and reduce the number of short-lived anti-apoptotic proteins, and cells are more sensitive to mitochondrial apoptosis. ${ }^{12,13}$ Studies have shown that in the early stage of fat grafting, about $20 \%$ of adipocytes undergo apoptosis. ${ }^{14,15}$ Therefore, it is of great significance to improve ADSCs survival rate after fat grafting, and patients will avoid repeated operations.

Berberine $\left(\left[\mathrm{C}_{2} \mathrm{H}_{18} \mathrm{NO}_{4}\right]^{+}, \mathrm{BBR}\right)$ is a natural isoquinoline alkaloid with a long history, which can be isolated from multiple herbal substances, such as Coptis and Phellodendron. BBR exerts multiple pharmacological effects on specific enzymes and receptors, including anti-cancer, antibacterial and lowdensity lipoprotein (LDL) reduction. ${ }^{16-18}$ The latest research has shown that BBR exhibits antioxidant effects on smooth muscle and mesangial cells. ${ }^{19,20}$

In previous studies, some antioxidants appear to improve fat survival rate; however, the effect of BBR on fat survival has not been reported before. ${ }^{5,21,22}$ In our research, for the first time, we established an in vitro $\mathrm{HY} / \mathrm{SD}$ ischemia model to investigate the effect of BBR on ADSCs apoptosis and autophagy, and further constructed in vivo models to confirm the function of BBR on transplanted adipose tissues. This research provides a new strategy for improving the survival of fat transplantation and may be applied in future clinical practice.

\section{Materials and Methods}

\section{Isolation and Culture of Human Adipose Derived Mesenchymal Stem Cells}

ADSCs were isolated from 3 liposuction patients at the Second Affiliated Hospital of Harbin Medical University. The obtained adipose tissue was washed with PBS, removed fiber composition, and then immersed in $0.2 \%$ collagenase solution (Sigma, St. Louis, MO, USA) at $37^{\circ} \mathrm{C}$ vibrating for $30 \mathrm{~min}$. After digestive termination, the cell solution was centrifuged at $1000 \mathrm{rpm}$ for $10 \mathrm{~min}$. Filtered with a $75-\mu \mathrm{m}$ filter mesh, then centrifuging at $1000 \mathrm{rpm}$ for $5 \mathrm{~min}$. Isolated ADSCs were cultured by a fresh complete medium DMEM/ F12 containing $10 \%$ fetal bovine serum (FBS, BD Biosciences). The cells were placed into a petri dish and incubated in $37^{\circ} \mathrm{C}$ humidified incubator with $5 \% \mathrm{CO}_{2}$. After $24 \mathrm{~h}$, we removed the non-adherent cells and cultured ADSCs routinely. ${ }^{23}$ The cells were subcultured when $80-90 \%$ confluence occurred in 5-7 days and the 3-5 generations were used for subsequent experiments. The study protocol was approved by the Ethics Committee of the Second Affiliated Hospital of Harbin Medical University, and samples were obtained with informed consent. We confirmed that all methods were performed in accordance with the relevant guidelines and regulations.

\section{Establishment of Vitro ADSCs Hypoxia Model and Drug Treatment}

In HY/SD group, increasing concentrations of BBR were preincubated with ADSCs for $1 \mathrm{~h}$ in DMEM/F12 (10\% FBS). Cells were washed with PBS and exposed to hypoxia conditions $\left(5 \% \mathrm{CO}_{2}\right.$ and $\left.95 \% \mathrm{~N}_{2}\right)$ provided by an air-tight modular incubator chamber (Billups-Rothenberg Inc., Del Mar, CA, USA) with a serum-free medium for $24 \mathrm{~h}$. In the control group, the cells were cultured in a complete medium at $37^{\circ} \mathrm{C} / 5 \% \mathrm{CO}_{2}$ for $24 \mathrm{~h}$. To administer the level of autophagy in ADSCs, 3-Methyladenine (3MA, $5 \mathrm{mM}$, MCE) and rapamycin $\left(100 \mathrm{nM}\right.$; MCE) were used, respectively. ${ }^{24}$ Moreover, compound $\mathrm{C}(10 \mu \mathrm{M}, \mathrm{MCE})$, the AMPK inhibitor, was 
added to further explore the molecular mechanism of autophagy and apoptosis in ADSCs.

\section{Cell Viability Assay}

Cell count kit-8 (CCK8) assay (Beyotime, Shanghai, China) was utilized to detect cell viability. The cells were pretreated with different concentrations of $\operatorname{BBR}(0,1,2,4,8,16,32$ and $64 \mu \mathrm{M})$ in complete medium for $1 \mathrm{~h}$, then incubated with serum-free medium under hypoxia conditions for 24 h. Added $10 \mu \mathrm{L}$ CCK8 reagent to each well and cultured at $37^{\circ} \mathrm{C}$ for $2 \mathrm{~h}$, then measured the absorbance at $450 \mathrm{~nm}$ using a multiplate reader (BioTek, CA, USA). ${ }^{25}$

\section{Detection of ROS Generation}

Once entered into a cell, the fluorescent probe $2^{\prime}, 7^{\prime}$ dichlorodihydrofluorescein diacetate (DCFH-DA) would be hydrolyzed into DCFH, which ulteriorly be oxidized to fluorescent DCF by intracellular reactive oxygen species (ROS). The medium was replaced with $1 \mathrm{~mL}$ DCFHDA (Beyotime, Shanghai, China) reagent and incubated at $37^{\circ} \mathrm{C}$ for $20 \mathrm{~min}$, washing 3 times with a serum-free medium to remove the DCFH-DA completely. The staining results were observed with a fluorescence microscope. $^{26}$

\section{Mitochondrial Membrane Potential Test}

$\mathrm{JC}-1$ is an ideal fluorescent probe for the detection of mitochondrial membrane potential $(\Delta \Psi \mathrm{m})$ whose accumulation in different locations would cause a transition between red fluorescence and green fluorescence, indicating the level of early apoptosis. ADSCs were treated under HY/SD conditions for $24 \mathrm{~h}$. After washing once with PBS, $2 \mathrm{~mL}$ thoroughly mixed mixture of JC-1 working solution (Beyotime, Shanghai, China) and fresh culture solution was added to each well. Incubating at $37^{\circ} \mathrm{C}$ for $20 \mathrm{~min}$, then rinsed twice with $\mathrm{JC}-1$ staining buffer $(1 \mathrm{x})$, followed by dropping $2 \mathrm{~mL}$ cell culture medium to each well. The staining results were observed with a fluorescence microscope. ${ }^{26}$

\section{Terminal Uridine Nick 3'-End Labelling}

During apoptosis, DNA would be degraded, producing low-molecular-weight double-stranded DNA fragments and high-molecular-weight DNA single-stranded nicks. DNA fragmentation was labeled with terminal deoxynucleotide transferase (TDT) and detected by the fab fragment of sheep anti-fluorescein antibody combined with horseradish peroxidase (POD). After HY/SD treatment, the cells were fixed with $4 \%$ paraformaldehyde at room temperature for $1 \mathrm{~h}$ and incubated with a blocking solution for $10 \mathrm{~min}$, then treated with $0.1 \%$ Triton $\mathrm{X}-100$ for $2 \mathrm{~min}$ on ice. Added 50 $\mu \mathrm{L}$ terminal uridine 3 'terminal labeling (Tunel) reaction mixture (Roche, Switzerland) to the dried samples and incubated at $37^{\circ} \mathrm{C}$ for $60 \mathrm{~min}$ in the dark. The staining results were observed and recorded under a fluorescence microscope (DMi8-M, Leica Microsystems, Wetzlar, Germany). ${ }^{27}$

\section{Western Blot Assay}

The soluble protein was prepared in RIPA lysis buffer (Beyotime, China) added with 1\% phenylmethanesulfonyl fluoride (PMSF) (Beyotime, China). Equivalent protein $(20-50 \mu \mathrm{g})$ was subjected to SDS-PAGE and transferred to electrophoretically PVDF membranes. After being immersed in blocking buffer (EpiZyme, China) at room temperature for $10 \mathrm{~min}$, the membranes were incubated with specific primary rabbit antibodies at $4{ }^{\circ} \mathrm{C}$ overnight. This is followed by incubating with secondary antibodies (1:5000, Beyotime, China) at room temperature for 1 h. Then, the antigen-antibody complex was detected by enhanced chemiluminescence (ECL) reagent. GAPDH and $\beta$-actin were used as loading controls. ${ }^{28}$ The primary antibodies were used as follows: GAPDH (1:5000, Abcam, UK), $\beta$-actin (1:5000, Abcam, UK), Bcl-2 (1:2000, Abcam, UK), Bax (1:3000, Abcam, UK), Beclin-1 (1:1000, CST, USA), LC3 (1:1000, CST, USA), P62 (1:1000, CST, USA), AMPK (1:1000, Waneibio, China), phospho-AMPK (1:1000, Waneibio, China), mTor (1:500, Waneibio, China), phospho-mTor (1:500, Waneibio, China).

\section{Immunofluorescence Staining Assay}

The ADSCs were seeded in a glass dish and prepared for the experiment. The cell was washed with phosphate buffered saline (PBS) and fixed with 4\% paraformaldehyde at room temperature for $15 \mathrm{~min}$. Then, the $0.5 \%$ Triton $\mathrm{X}-100$ was used to permeate ADSCs membranes for 20 min. After goat serum was blocked at $37^{\circ} \mathrm{C}$ for $30 \mathrm{~min}$, the cells were soaked with LC3 antibody (1:200, CST, USA) at $4^{\circ} \mathrm{C}$ overnight, followed by incubated with fluorescent secondary antibody at $37^{\circ} \mathrm{C}$ for $1 \mathrm{~h} .4^{\prime}, 6$-Diamidine-2'phenylindole dihydrochloride (DAPI, C1002, Beyotime) was used to stain the cell nucleus. The 
immunofluorescence photographs were captured by a confocal microscope (Olympus FV1000, Japan). ${ }^{29}$

\section{Establishment of Animal Models}

Animal models were established based on institutional protocols and approved by the Animal Ethics Committee of the Second Affiliated of Harbin Medical University (SYDW2021-093) and conducted in accordance with the Measures for the Administration of Laboratory Animals at Harbin Medical University. For vivo experiments, twenty females, six to eight-week-old BALB/c nude mice (Weitong Lihua Laboratory Animal Technology Co., Ltd., Beijing) were used. According to our previous study, $4 \mu \mathrm{M}$ BBR was prepared for animal experiments. Fat processing method is in accordance with the Coleman procedure. ${ }^{30-32}$ Adipose tissue was obtained from the abdomen or thighs of healthy female patients undergoing liposuction operation, and all patients signed an informed consent form. Luer-Lok is a converter to connect $5 \mathrm{~mL}$ syringes. After 30 passes, the granular fat gradually becomes an emulsion. The emulsified nanofat was placed in a sterile gauze to filter out excess water. Took out a part of the nanofat and soaked in $4 \mu \mathrm{M}$ BBR solution at $37^{\circ} \mathrm{C}$ for $10 \mathrm{~min}$ then transferred it into $1 \mathrm{~mL}$ syringes through the converter. The mice were randomly divided into the control group and the BBR treatment group. Each injection point was injected with $200 \mu \mathrm{L}$ nanofat. Calculated the volume and weight of fat grafting. The two groups were injected with $0.9 \% \mathrm{NaCl}$ solution and BBR solution subcutaneously in the recipient area from the first day after surgery for 7 days. To observe the survival status of fat grafting, mice were sacrificed at 14 and 28 days.

\section{Hematoxylin-and-Eosin-Stained and Immunohistochemical Analysis}

The adipose tissue was fixed with $4 \%$ paraformaldehyde solution, then embedded in paraffin and cut into $4 \mu \mathrm{m}$ sections. Hematoxylin eosin staining was performed to observe levels of adipose tissue fibrosis and inflammatory infiltration. The rabbit anti-perilipin antibody (1:200, CST, USA) and anti-CD31 antibody (1:200, Affinity, USA) were used for immunohistochemical staining to assess adipocytes survival rate and angiogenesis, respectively. Taken pictures under an optical microscope.

\section{Statistical Analysis}

All data were analyzed with SPSS version 19.0 software (IBM Corp., Armonk, NY, USA) or GraphPad Prism 7.0 software and presented as mean $\pm \mathrm{SD}$. Comparison between groups was assessed using two-tailed paired or non-paired Student's $t$ test. P-value less than $0.05(\mathrm{P}<0.05)$ was considered to indicate a significant difference.

\section{Results}

\section{Characterization of ADSCs}

ADSCs were separated from human adipose tissue and gradually adhered to culture-coated plates with a complete medium. The adherent cells were morphologically defined by a fibroblast-like appearance in spindle shape at third passage and grew vigorously. ${ }^{33}$ The growth curve of separated ADSCs was S-shaped. Characterization by flow cytometric analysis indicated that most separated cells were positive for CD90, CD105 and negative for CD34, CD14 (Figure 1A).

\section{BBR Reversed the Decrease in Cell Survival Rate Caused by HY/SD}

CCK8 assay was used to determine the cell viability of ADSCs in HY/SD conditions. BBR treatment alone had no impact on normoxia ADSCs. Compared with the normoxia group, cell viability decreased significantly in HY/SD conditions, and the cell survival rate increased after BBR treatment. The highest cell viability was obtained when the concentration of BBR reached $4 \mu \mathrm{M}$ (Figure 1B). Therefore, we chose $4 \mu \mathrm{M}$ to perform all subsequent experiments.

\section{BBR Reduced ROS Production Under HY/SD Conditions}

ROS is a key component of the pro-apoptotic signaling cascade, which also plays a vital role in cell survival. The results demonstrated that HY/SD obviously promoted the generation of ROS in ADSCs, while BBR significantly inhibited the process (Figure 1C). These data illustrated that BBR would provide protection by reducing the production of ROS.

\section{The Effect of BBR on Cell Apoptosis and Autophagy}

To investigate the effect of BBR on ADSCs apoptosis and under $\mathrm{HY} / \mathrm{SD}$ conditions, $\Delta \Psi \mathrm{m}$ was used to detect the anti-apoptotic effect of BBR on ADSCs. Compared with the control group, HY/SD caused a significant increase in cell apoptosis, while BBR treatment could significantly reduce this effect (Figure 1D). In order to 
A

CD90

CD105

CD34

CD14
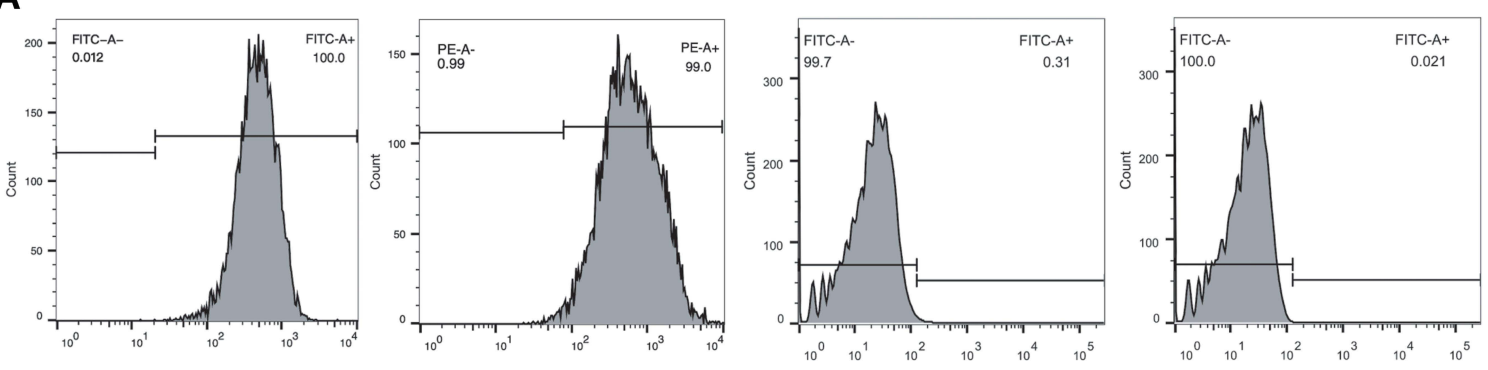

B
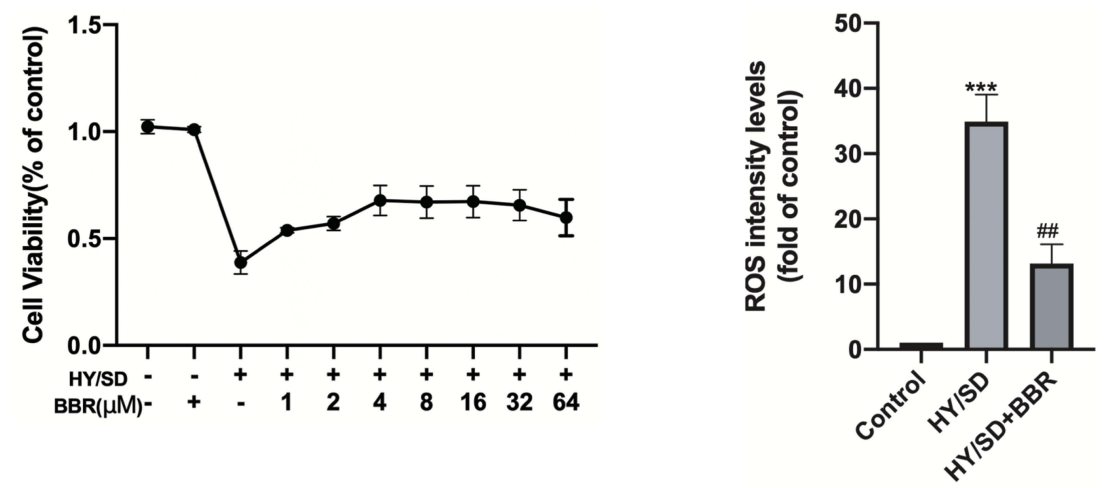

C
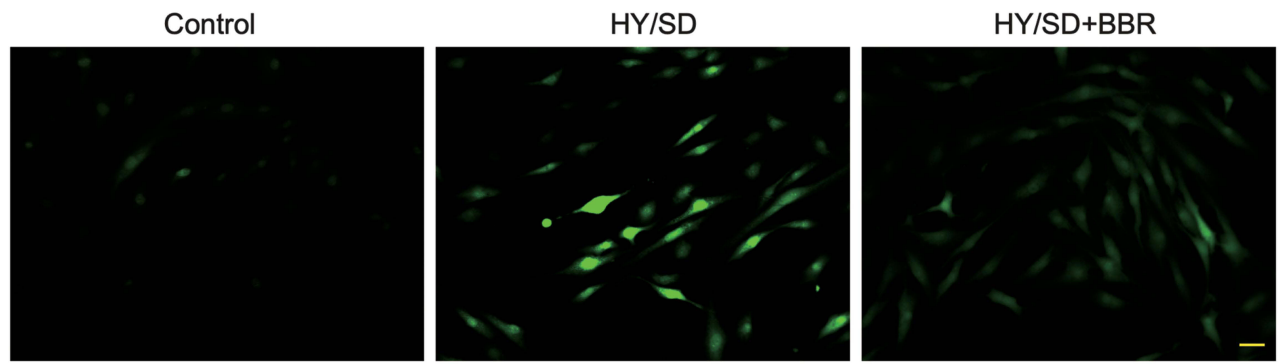

D

JC-1 monomer

JC-1 aggregate

Merge
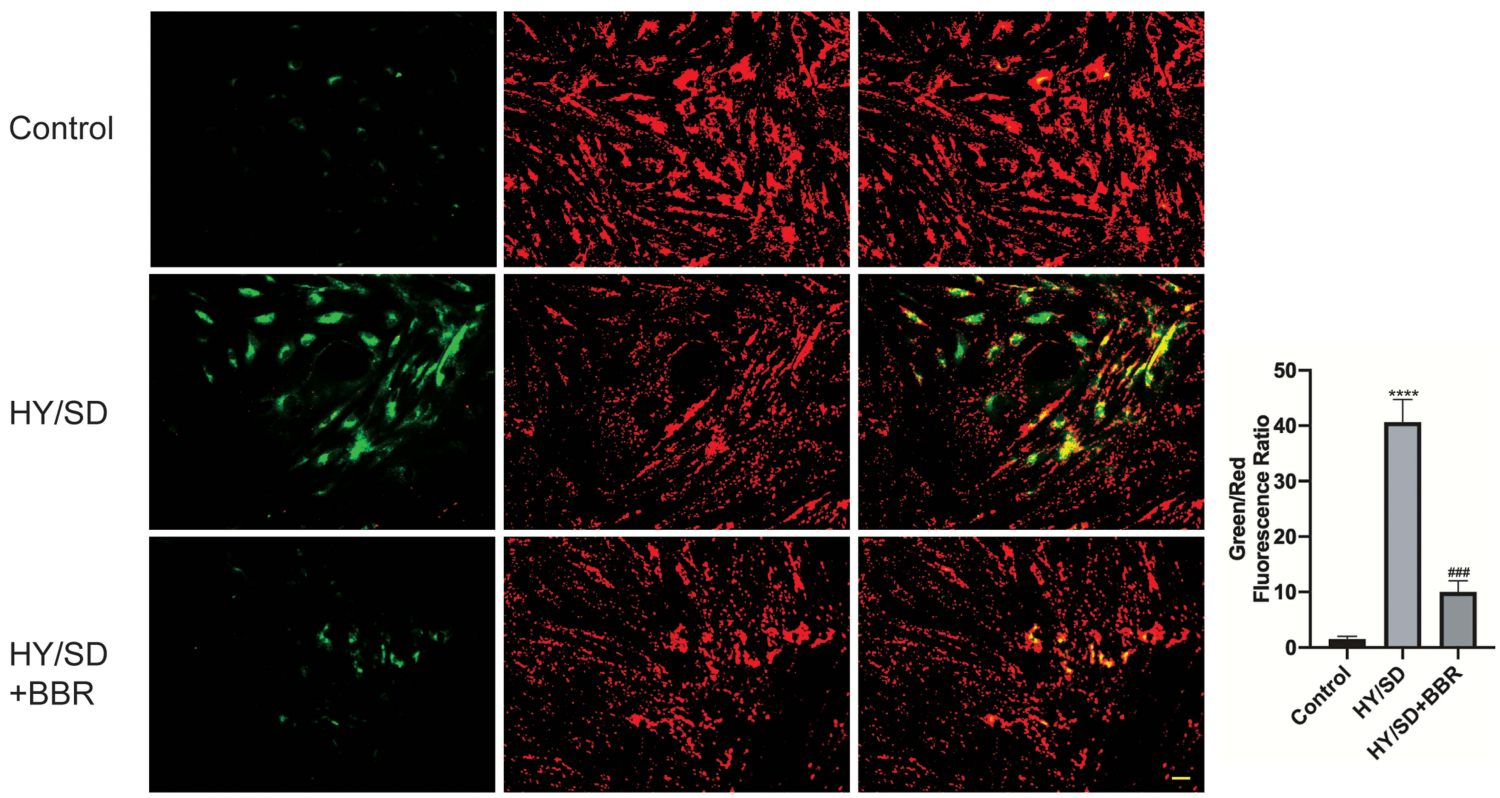

Figure I Berberine can alleviate the decrease in cell survival rate induced by HY/SD and reduce the production of ROS and $\triangle \Psi m$. (A) Flow cytometric analysis of surface antigen expression on ADSCs. ADSCs expressed CD90, CDI05 and negative for CD34 and CDI4. (B) The ADSCs viability was determined by CCK-8 assay and detected at $24 \mathrm{~h}$ after incubation under HY/SD conditions and treated with different doses of BBR. (C) The production of mitochondrial ROS in treated ADSCs (Scale Bar $=25 \mu \mathrm{m})$. (D) $\triangle \Psi \mathrm{m}$ was

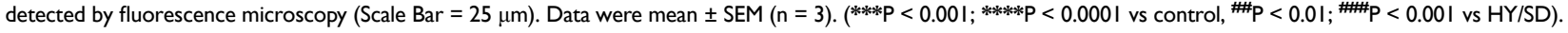


confirm the anti-apoptotic impact of BBR, we conducted a Western blot experiment. After HY/SD for $24 \mathrm{~h}$, results showed that the expression of Bcl-2 was decreased, while the expression of pro-apoptotic protein Bax increased, suggesting that the apoptosis process of
ADSCs was initiated. Meanwhile, after pretreatment with $4 \mu \mathrm{M}$ BBR for $1 \mathrm{~h}$, the expression of $\mathrm{Bcl}-2$ increased and Bax decreased, indicating that cell apoptosis was alleviated by BBR (Figure 2A). The above conclusion indicated that BBR would play an anti-

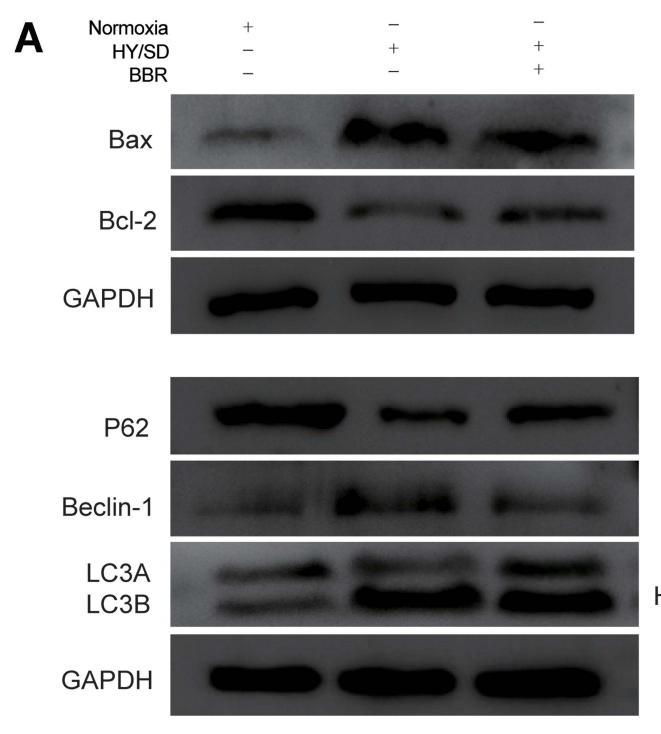

B

Tunel
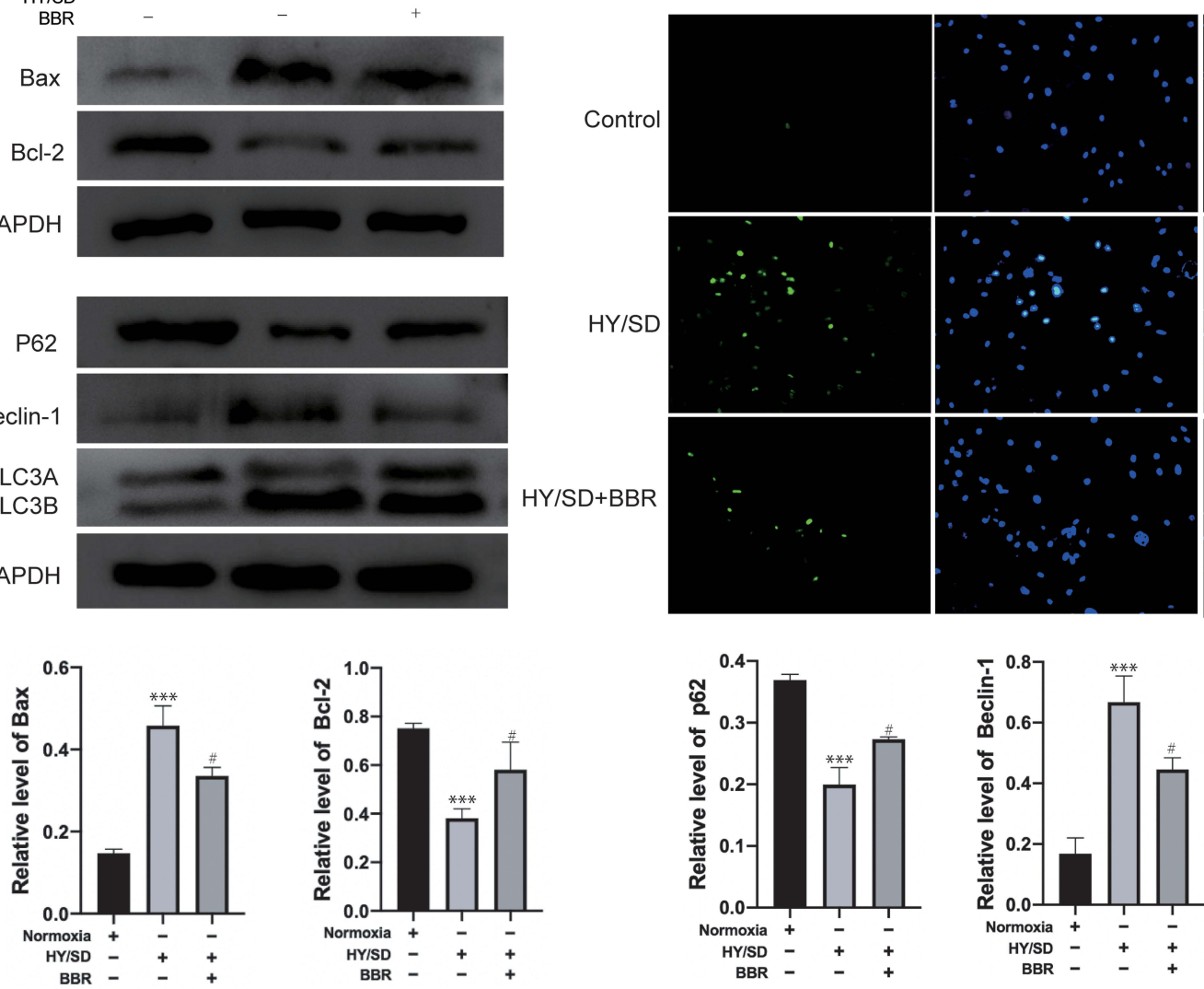

C

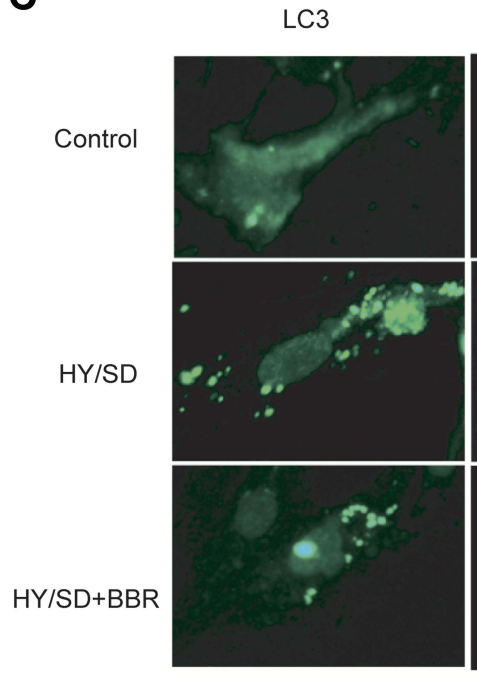

DAPI

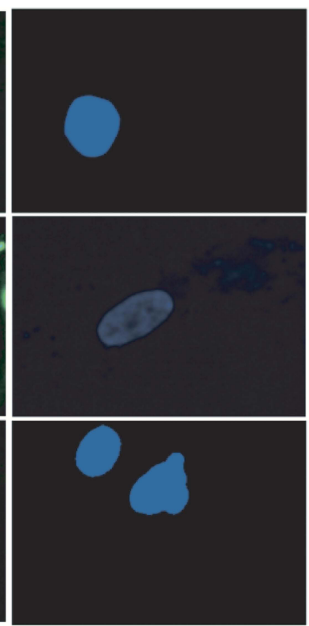

Merge

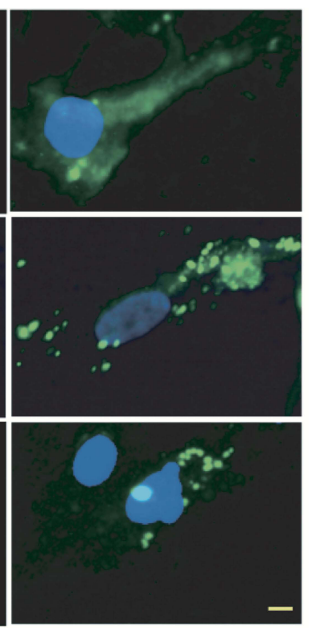

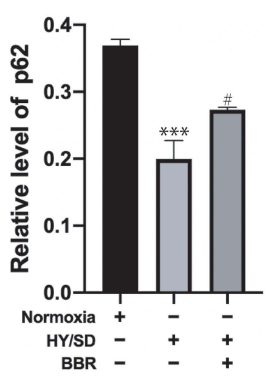
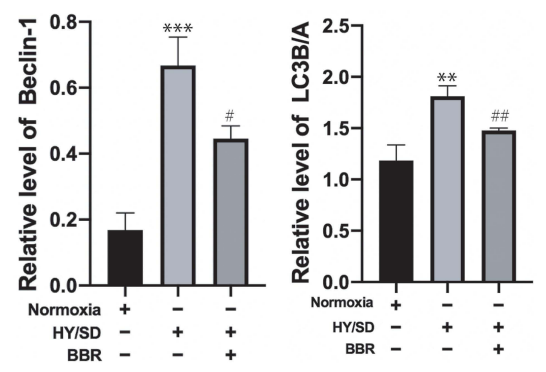

Figure 2 BBR can reverse apoptosis and autophagy induced by HY/SD. (A) The expression of apoptosis and autophagy-related proteins was detected by Western blotting. GAPDH served as a control. (B) The apoptosis was detected by using Tunel test (Scale Bar $=25 \mu \mathrm{m}$ ). (C) LC 3 immunofluorescence staining on ADSCs (Scale Bar $=5 \mu \mathrm{m})$.

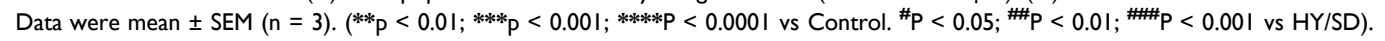
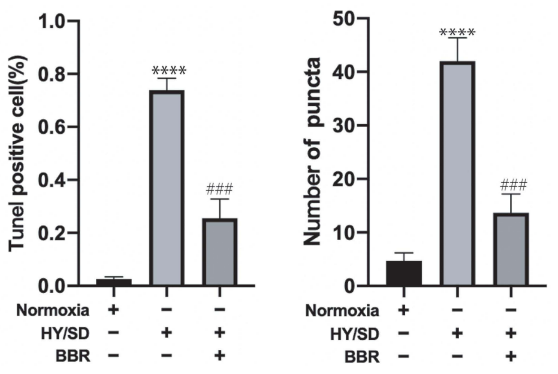
apoptotic role in ADSCs in an ischemic environment. Similar conclusions were also observed in the Tunel experiment (Figure 2B).

To further investigate the effect of BBR on autophagy in an ischemic environment, we tested the expression of autophagy markers in ADSCs. As shown in the LC3 immunofluorescence images, autophagy flux was monitored by analyzing green fluorescence signals. Under HY/SD conditions, the number of green puncta significantly increased, suggesting a conversation between LC3A and LC3B. However, after BBR treatment, the number of green puncta in ADSCs is significantly reduced (Figure 2C). Western blot analysis also supported the above conclusions. HY/SD could induce the expression level of LC3B/A, Beclin-1 and decrease P62 expression. However, after BBR addition, the protein expression level of LC3B/A and Beclin-1 declined, and P62 raised (Figure 2A). In general, HY/SD would induce apoptosis and autophagy in ADSCs and BBR could alleviate these processes.

\section{Autophagy Contributed to the Apoptosis of ADSCs Induced by HY/SD Conditions}

Our studies have shown that under HY/SD conditions, BBR attenuates the autophagy and apoptosis of ADSCs. However, it is unclear whether a crosstalk existed between apoptosis and autophagy. The autophagy promoter rapamycin and autophagy inhibitor 3-MA were incubated separately, followed by BBR treatment for 2 $\mathrm{h}$ before hypoxia. Western blot assay showed that under rapamycin and 3-MA intervention, the autophagy level changed accordingly. 3-MA reduced the expressions of LC3B/A and Beclin-1, whereas increased the P62 expression. The opposite result was obtained under the action of rapamycin, the expression of $\mathrm{LC} 3 \mathrm{~B} / \mathrm{A}$, Beclin-1 increased and P62 declined (Figure 3A). LC3 immunofluorescence results showed 3-MA could block the formation of LC3 induced by hypoxia, while rapamycin would aggravate LC3 production (Figure 3B). In conclusion, rapamycin and 3-MA could regulate the autophagy level of ADSCs in an $\mathrm{HY} / \mathrm{SD}$ environment.

Our research also proved that under the regulation of autophagy promoter and inhibitor, the level of apoptosis is altered accordingly. Compared with HY/SD $+\mathrm{BBR}$ group, 3-MA inhibited Bax and promoted the expression of $\mathrm{Bcl}-2$, rapamycin elevated $\mathrm{Bax}$ and reduced Bcl-2 expression (Figure 3C). In addition, after 3-MA treatment, the number of Tunel positive cells was lower than that of the group without 3-MA treatment, which is subsequently aggravated by rapamycin (Figure 3D). In summary, autophagy promoted the apoptosis of ADSCs induced by HY/SD after BBR treatment.

\section{BBR Regulated Autophagy and Apoptosis by AMPK/mTOR Pathway}

To investigate the potential mechanism of ADSCs induced by HY/SD, Western blot assay was conducted. The results indicated that hypoxic stress could activate AMPK/mTor signaling pathway. Compared with the normoxic group, phospho-AMPK (p-AMPK) expression increased and phospho-mTor (p-mTor) expression decreased after starving ADSCs. Conversely, the situation changed after BBR incubation (Figure 4A).

To further verify AMPK/mTor signal pathway whether regulated autophagy and apoptosis, we used rapamycin and compound $\mathrm{C}$ as mTor and AMPK inhibitors, respectively. ADSCs were pretreated with rapamycin or compound $\mathrm{C}$, then incubated with BBR for $2 \mathrm{~h}$ followed by hypoxia for 24 h. Western blot results revealed that compound $\mathrm{C}$ reduced the expression of $\mathrm{p}$-AMPK and promoted $\mathrm{p}$-mTor expression. Rapamycin inhibited the expression of p-mTor. However, it does not affect p-AMPK (Figure 4B). These results indicated that rapamycin and compound $C$ could suppress the expression of p-mTor and p-AMPK. According to the results of LC3 immunofluorescence, Tunel assay and Western blot, we proved that rapamycin could enhance the apoptosis and autophagy activity of ADSCs under HY/SD conditions, while compound $\mathrm{C}$ attenuated both of the above activities (Figure 4C-F). Taken together, these experimental data demonstrated that under HY/ SD conditions, the AMPK/mTor pathway had an effect on autophagy and apoptosis of ADSCs, and BBR played a role through this pathway.

\section{Volume and Weights of the Fat Grafting}

The injection sites we chose for fat grafting were the neck and the back of mice (Figure 5). There were no significant differences in injection volume and weight between the groups. The fat absorption rate of the neck receptor was higher than that of the back, which might be due to the neck receptor being more active than the back one (Figure 6). The results showed that the fat volume and weight of the BBR group was greater than the control group after surgery (Table 1). 
A
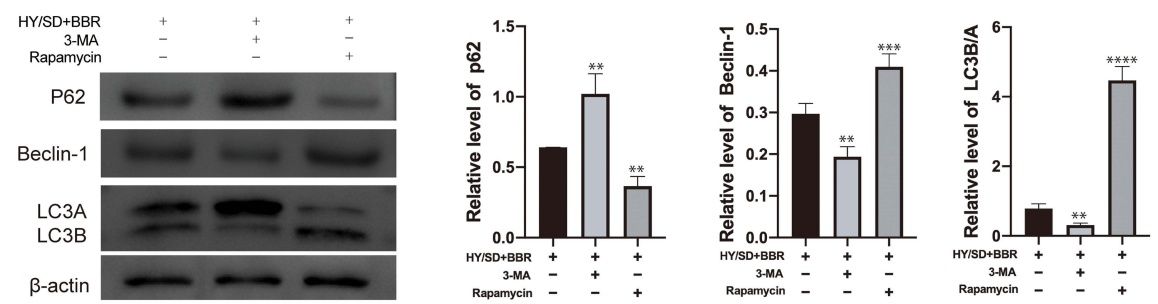

B

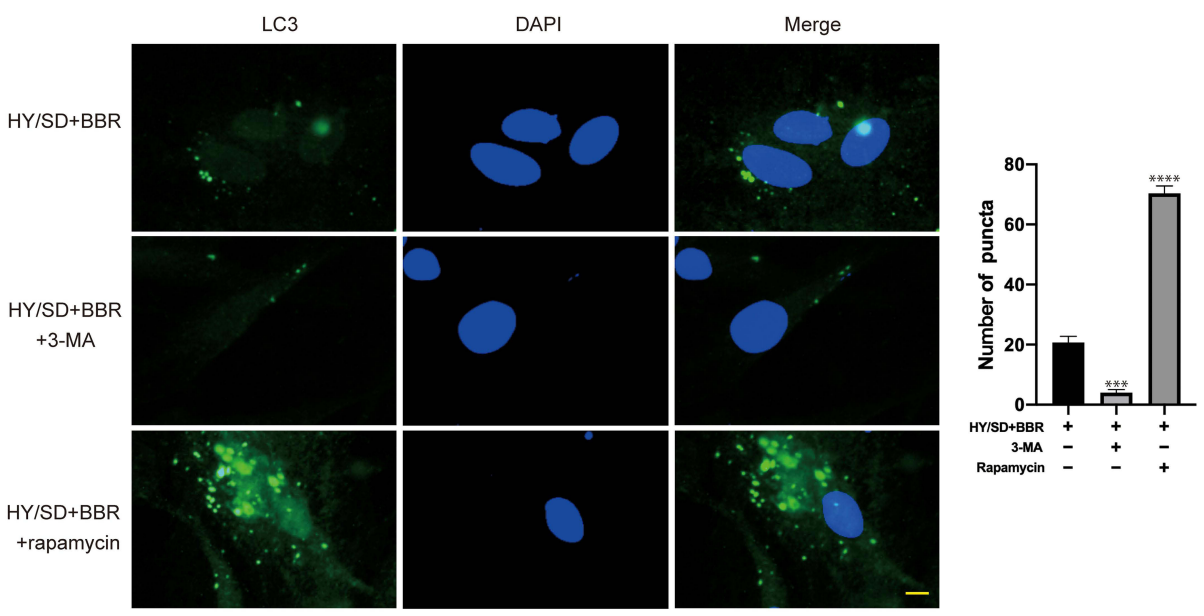

C

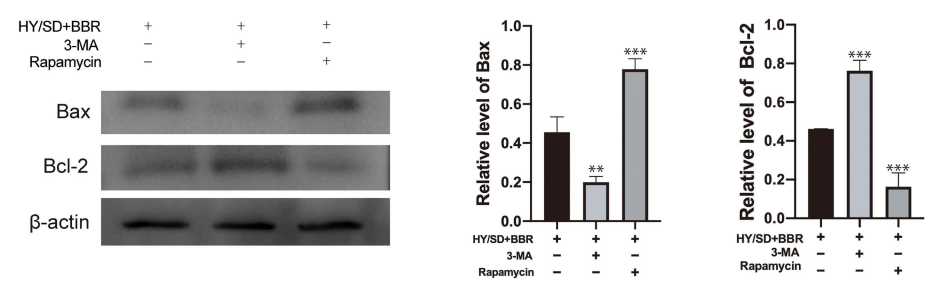

D

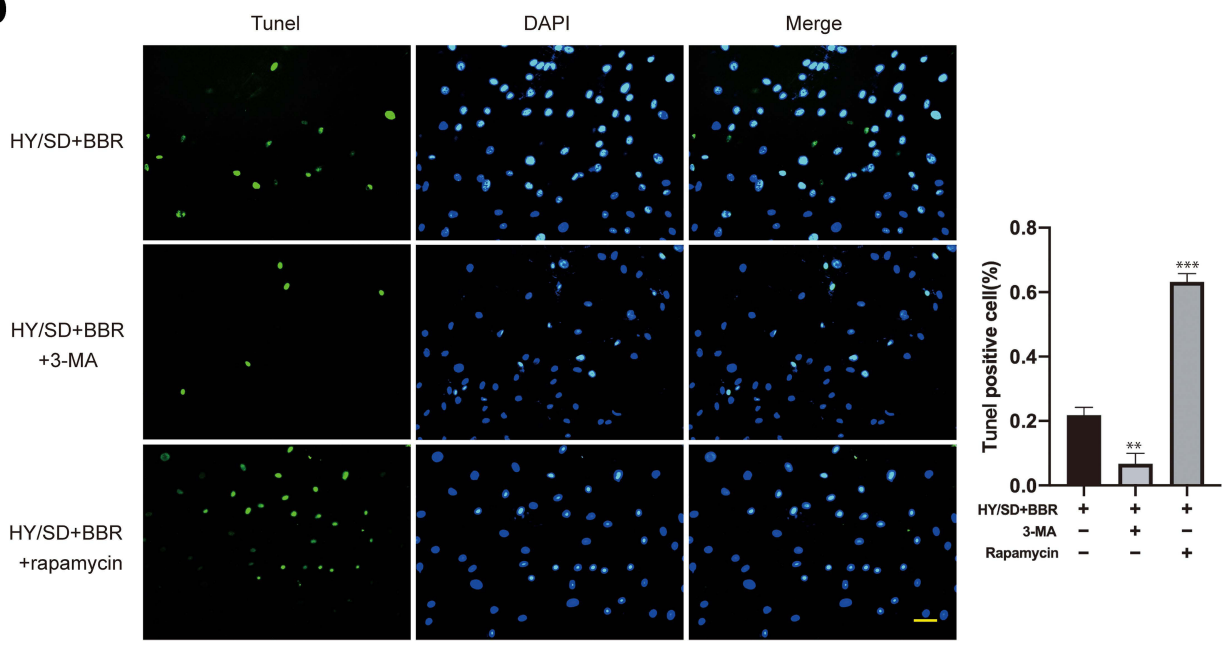

Figure 3 Apoptosis of ADSCs induced by HY/SD conditions can be affected by autophagy. (A) Western blot assay of autophagy related proteins expression in ADSCs incubated with rapamycin and 3-MA separately, followed by BBR pretreatment for $2 \mathrm{~h}$ before hypoxia. $\beta$-actin served as a control. (B) LC3 immunofluorescence in ADSCs for different processing groups (Scale Bar $=5 \mu \mathrm{m}$ ). (C) Western blot assay of Bax and Bcl-2 expression in ADSCs for different processing groups. $\beta$-actin served as a control. (D) Tunel assay in different treatment ADSCs groups. Data were mean \pm SEM $(n=3)$. (**P $<0.01$; ****P $<0.00$ I; ****P $<0.000$ I vs HY/SD+BBR group).

\section{Histological Results}

Based on the results of histological hematoxylin eosin staining, compared with the control group, a lower level of fibrosis was observed in the BBR group. After surgery, BBR injection can significantly reduce fibrosis degree and improve fat survival. Beyond that, we concluded that the inflammatory cell 


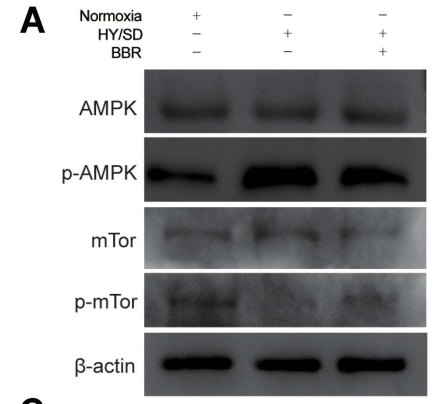

C
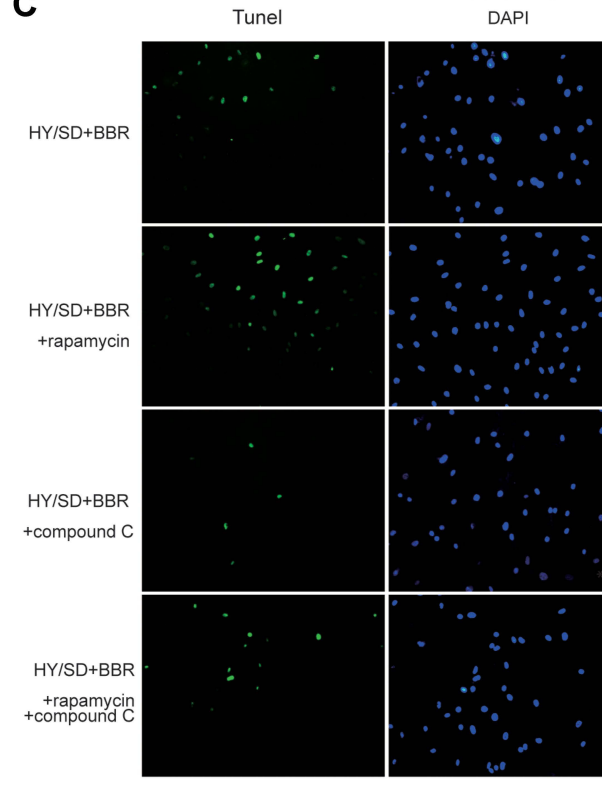

E
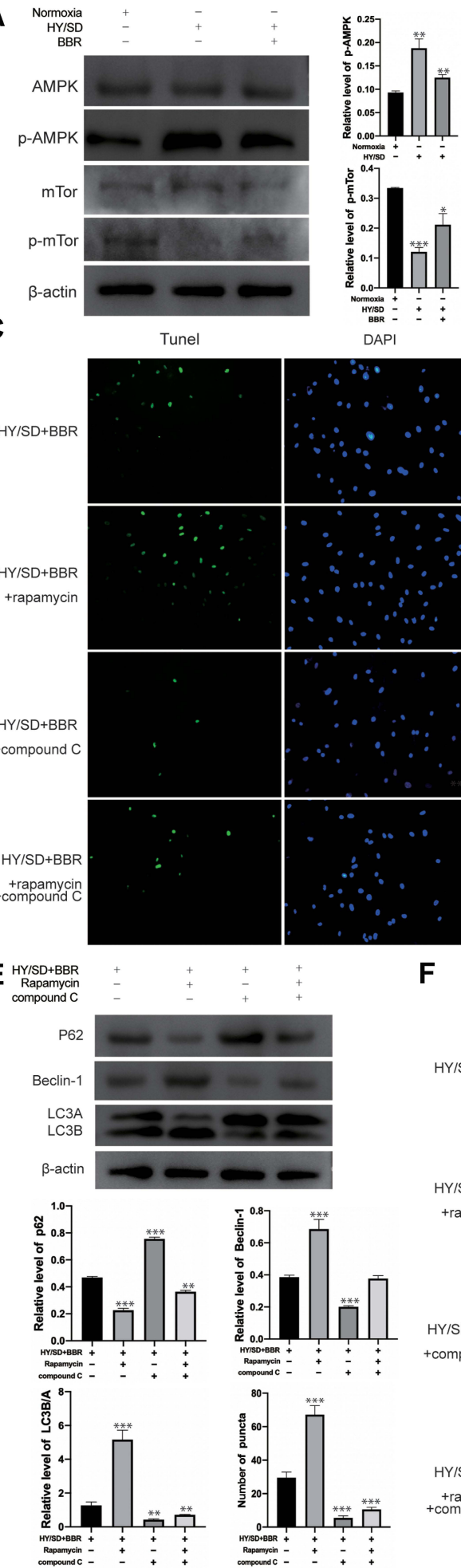

$\mathbf{F}$
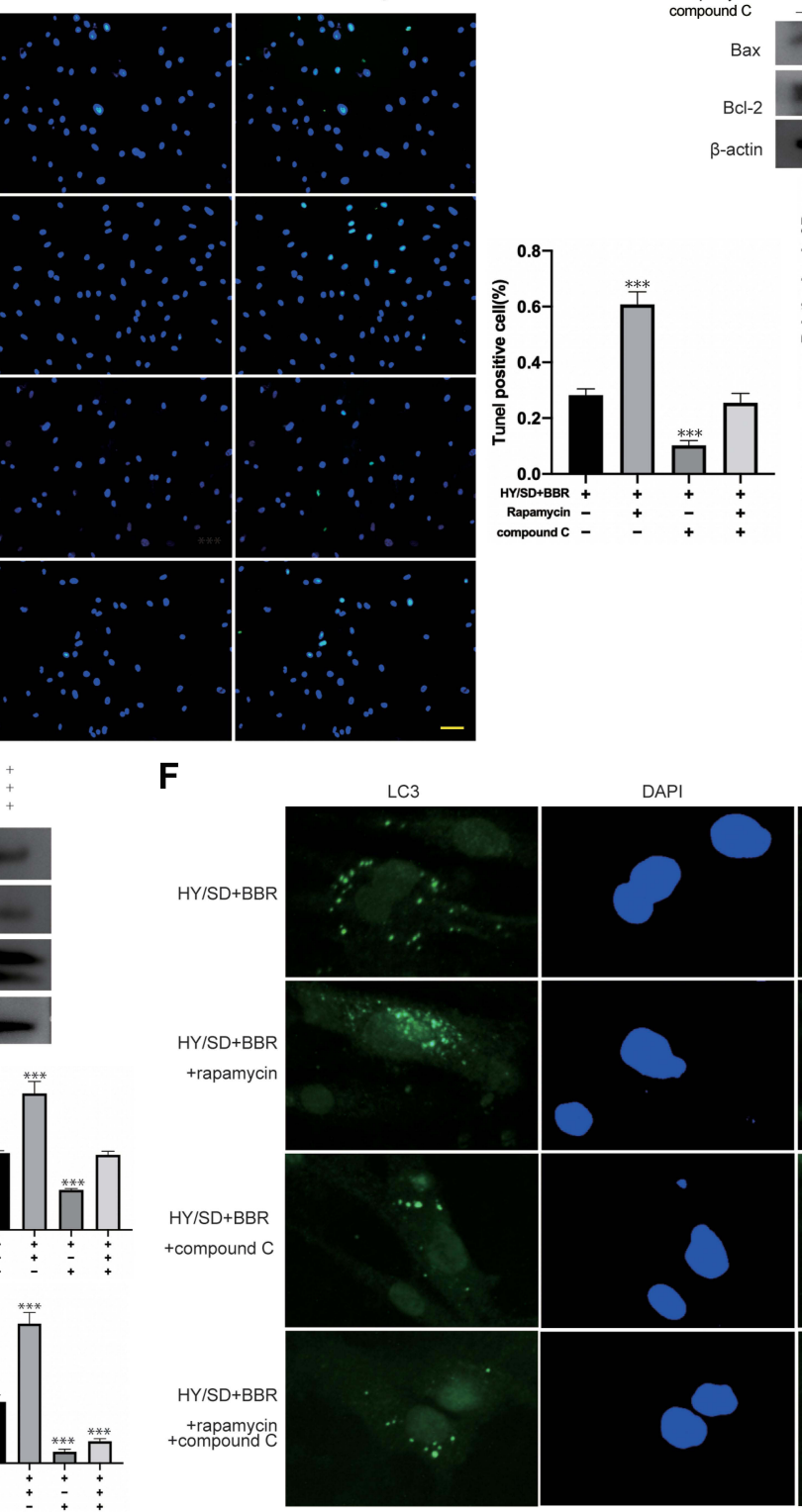

B
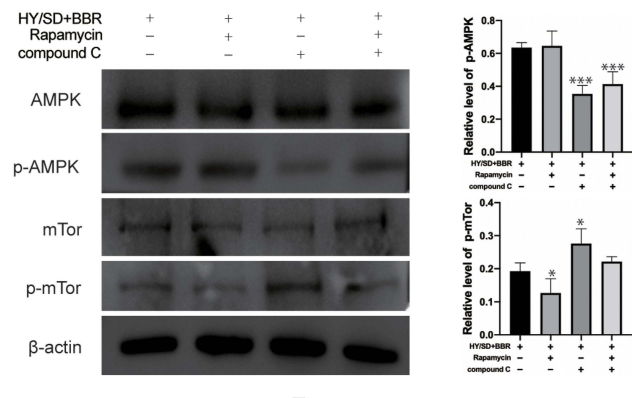

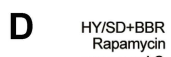
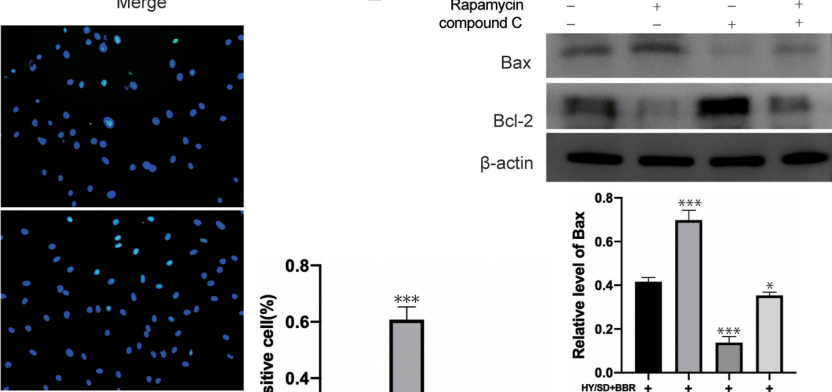

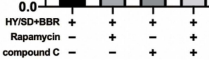

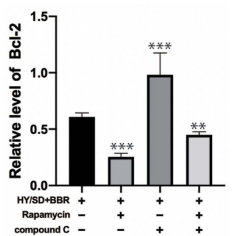

Figure 4 Under HY/SD conditions, BBR regulate autophagy and apoptosis of ADSCs through the AMPK/mTor pathway. (A) The expression of p-APMK and p-mTor under HY/SD conditions. $\beta$-actin served as a control. (B) The expression of $\mathrm{p}$-APMK and $\mathrm{p}$-mTor in ADSCs incubated with the rapamycin and compound C. $\beta$-actin served as a control. (C) Tunel assay in different treatment ADSCs groups (Scale Bar $=25 \mu \mathrm{m}$ ). (D and E) The expression of apoptosis and autophagy-related proteins in ADSCs for different processing groups. $\beta$-actin served as a control. (F) LC3 immunofluorescence in different treatment ADSCs groups. (Scale Bar = $5 \mu$ m). Data were mean \pm SEM $(\mathrm{n}=3)$. ( $* \mathrm{P}<0.05 ; * * \mathrm{P}<0.01 ; * * * \mathrm{P}<0.001$ vs $\mathrm{HY} / \mathrm{SD}+\mathrm{BBR}$ group). 

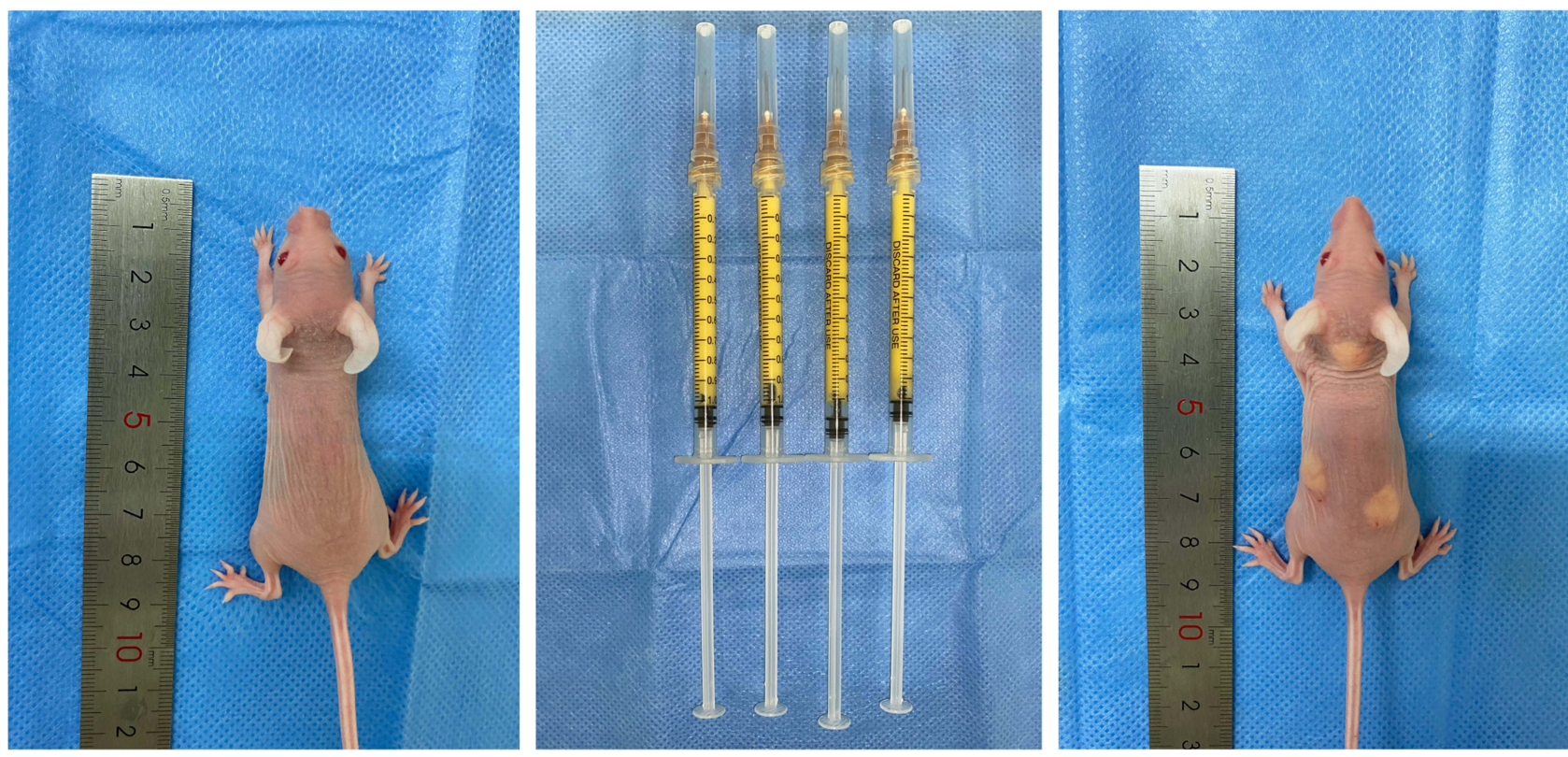

Figure $\mathbf{5}$ The human derived fat tissue was prepared for experiment in vivo.

infiltration and the degree of fibrosis in the BBR group were lower than those in the control group (Figure 7A).

\section{Survival Rate of Fat Tissue and Angiogenesis}

Perilipin staining results showed that the survival rate of adipocytes in the BBR group was higher than that in the control group. The adipocytes were intact, with less inflammatory cell infiltration and a low degree of tissue fibrosis (Figure 7B). CD31 staining was used to evaluate the degree of angiogenesis (Figure 8). In the control group, obvious fat liquefaction and vacuoles were observed at POD14, and no mature angiogenesis was detected. However, in the BBR group, blood vessels were obvious. At POD28, compared with the control group, blood vessels survived around mature adipocytes with low fibrosis after BBR injection.

\section{Discussion}

BBR is an isoquinoline alkaloid that exists in multiple plants, such as coptis, berberis, phellodendron and turmeric. According to "Shen Nong Chinese Herbal Medicine", about 2000 years ago, coptis have been used to treat certain diseases, including abdominal distension, diarrhea, vomiting, and irritability. Recent studies have re-evaluated the biological functions of BBR, confirming that it can regulate cell cycles and autophagy, thereby inhibiting tumor cell proliferation and promoting apoptosis. ${ }^{34-38}$ BBR can also reduce the proliferation of helicobacter pylori to protect the gastric mucosal membrane, ${ }^{39}$ affect the hemodynamics of cardiovascular system, lower blood pressure and improve the prognosis of arrhythmias caused by myocardial ischemia. ${ }^{40,41}$ In addition, BBR promoted the recruitment and activation of brown adipose tissue, inhibiting the progression of inflammation and fibrosis. ${ }^{42,43}$ In order to further explore the effect of BBR on ADSCs under nutrient deficient conditions, we established ischemia model in vitro, confirmed the activity of ADSCs was obviously inhibited under the condition of nutrient deficiency, demonstrated that hypoxia and serum-free conditions would induce ADSCs apoptosis and autophagy, and proved that BBR could protect against ischemia mediated injury by alleviating above situations.

There is a complex interactive regulation between autophagy and apoptosis, which share multiple regulatory molecules, be activated by the same stress stimuli, and even coordinate transformation with each other. Comprehensive and in-depth research of the interaction mechanism between autophagy and apoptosis will bring breakthrough progress in the cognition and clinical application of cell transplantation. ${ }^{44}$ Hypoxic and ischemia would cause excessive ROS production, even cell apoptosis. ${ }^{45-47}$ Remarkably, ROS increase caused by catalase degradation is one of the autophagy characteristics. ${ }^{48}$ Our research proved that under HY/SD situation, there was a crosstalk between ADSCs apoptosis and autophagy, which would be adjusted by BBR through AMPK/mTor 

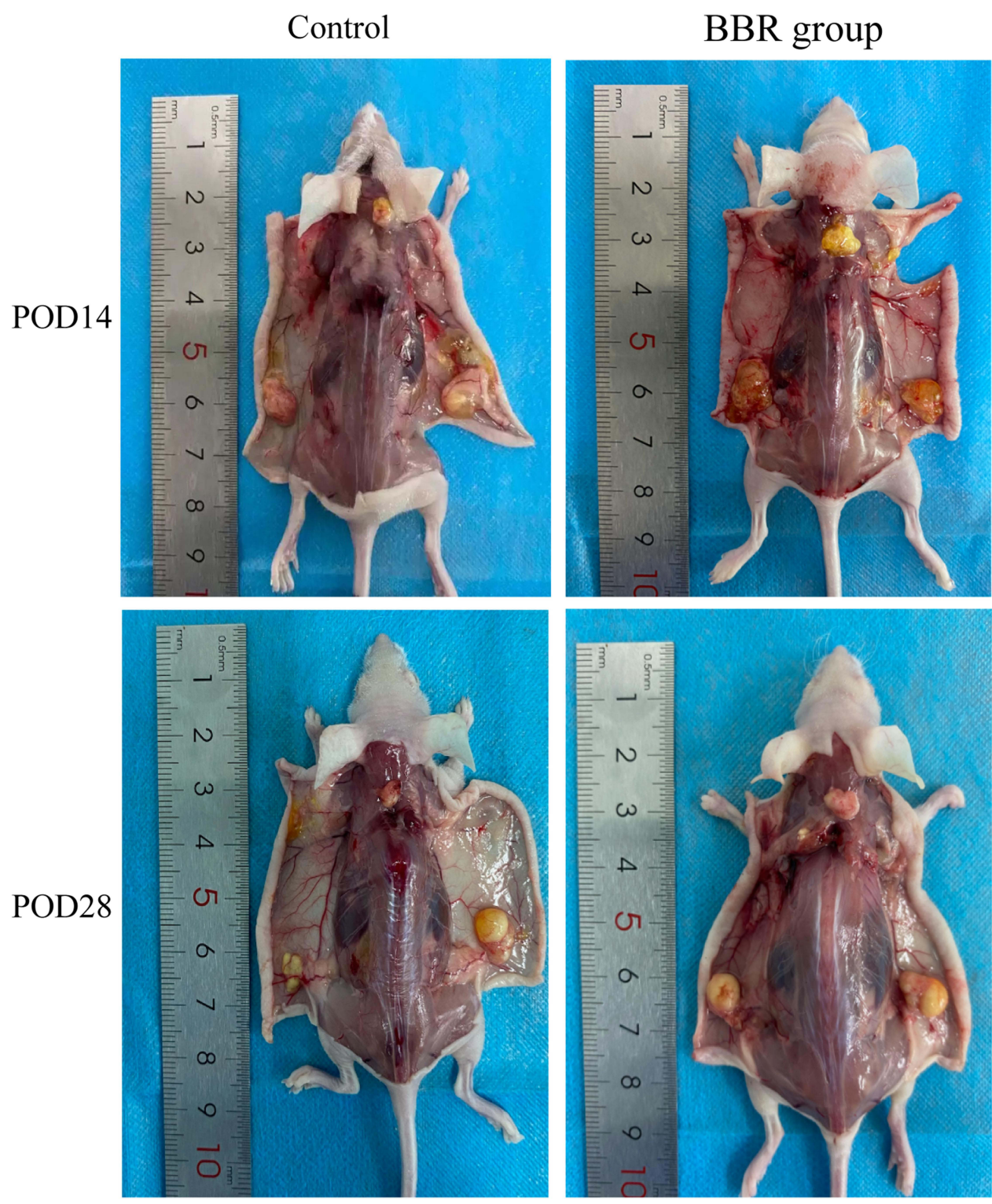

Figure 6 Anatomy of fat grafting site after operation.

signaling pathway. AMPK is widely expressed in eukaryotic cells. Under nutrient deficiency and physical stimulation, it is activated to regulate the catabolic process and maintain the balance of the intracellular environment. ${ }^{49} \mathrm{In}$ this process, activated AMPK directly phosphorylates TSC2 and RAPTOR to block mTor activation, inhibiting the mTor protein kinase complex, and thereby adjusting autophagy activity. ${ }^{50}$ Indeed, our research confirmed this point. HY/SD conditions induced the upregulation of p-AMPK and inhibited p-mTor expression, while BBR could inhibit this process.

Previous studies have elucidated the mechanism of fat grafting survival and proposed two theories. ${ }^{51,52}$ Peer demonstrated that the key point of survival rate was to establish early blood circulation. Another concept is the Graft Replacement Theory, whose theoretical support relies on ADSCs. After grafting, adipose tissue in the recipient area was divided into three zones: surviving zone, regenerating zone and necrotic zone. ADSCs were located in the fat regeneration zone, which activate and regenerate adipocytes. Tonnard confirmed that adipocytes would no longer survive after fat emulsification; however, the activities of ADSCs and vascular matrix components were comparable to standard liposuction techniques. ${ }^{53}$ In the case of insufficient blood supply, ADSCs become the main growth point of fat grafting when all adipocytes undergo degenerative changes and are prone to death. Therefore, improving the survival rate of ADSCs is critical to the ultimate effect of fat grafting. In 2018, Ghorbani A placed ADSCs in 
Table I The Weight and Volume Variation of Fat Graft Between Control and BBR Groups

\begin{tabular}{|c|c|c|c|c|c|c|c|c|}
\hline \multirow[t]{2}{*}{ POD } & \multirow[t]{2}{*}{ Injection Site } & \multirow[t]{2}{*}{ Group } & \multicolumn{2}{|c|}{ Weight (mg) } & \multirow[t]{2}{*}{$P$} & \multicolumn{2}{|c|}{ Volume $(\mu \mathrm{L})$} & \multirow[t]{2}{*}{$P$} \\
\hline & & & Preoperation & Postoperation & & Preoperation & Postoperation & \\
\hline \multirow[t]{4}{*}{ PODI4 } & \multirow[t]{2}{*}{ Neck } & Control & \multirow[t]{2}{*}{$2.01 \pm 0.04$} & $0.53 \pm 0.11$ & \multirow[t]{2}{*}{$0.001 *$} & \multirow[t]{2}{*}{200} & $61.00 \pm 9.46$ & \multirow[t]{2}{*}{$0.001 *$} \\
\hline & & BBR & & $1.00 \pm 0.15$ & & & $112.6 \pm 6.02$ & \\
\hline & \multirow[t]{2}{*}{ Back } & Control & \multirow[t]{2}{*}{$2.00 \pm 0.08$} & $1.25 \pm 0.09$ & \multirow[t]{2}{*}{$0.05 *$} & \multirow[t]{2}{*}{200} & $|6| . \mid \pm 8.93$ & \multirow[t]{2}{*}{0.15} \\
\hline & & BBR & & $1.37 \pm 0.09$ & & & $166.7 \pm 7.88$ & \\
\hline \multirow[t]{3}{*}{ POD28 } & \multirow[t]{2}{*}{ Neck } & Control & \multirow[t]{2}{*}{$1.96 \pm 0.05$} & $0.36 \pm 0.05$ & \multirow[t]{2}{*}{$0.001 *$} & \multirow[t]{2}{*}{200} & $38.20 \pm 2.58$ & \multirow[t]{2}{*}{$0.001 *$} \\
\hline & & BBR & & $0.86 \pm 0.11$ & & & $91.60 \pm 6.18$ & \\
\hline & Back & $\begin{array}{l}\text { Control } \\
\text { BBR }\end{array}$ & $1.95 \pm 0.05$ & $\begin{array}{l}0.58 \pm 0.14 \\
1.08 \pm 0.13\end{array}$ & $0.001 *$ & 200 & $\begin{array}{l}81.40 \pm 9.76 \\
139.4 \pm 6.85\end{array}$ & $0.001 *$ \\
\hline
\end{tabular}

Notes: Values are presented as Mean \pm SD. $* \mathrm{P}<0.05$.

Abbreviation: POD, postoperative day.

glucose and serum deprivation (GSD) conditions to induce cell death, suggesting that GSD conditions significantly reduced the viability of ADSCs and increased the production of ROS and apoptosis. ${ }^{54}$ On this basis, we further studied the mechanism of BBR under HY/SD conditions and established an in vivo model to evaluate the role of BBR in fat grafting.
A

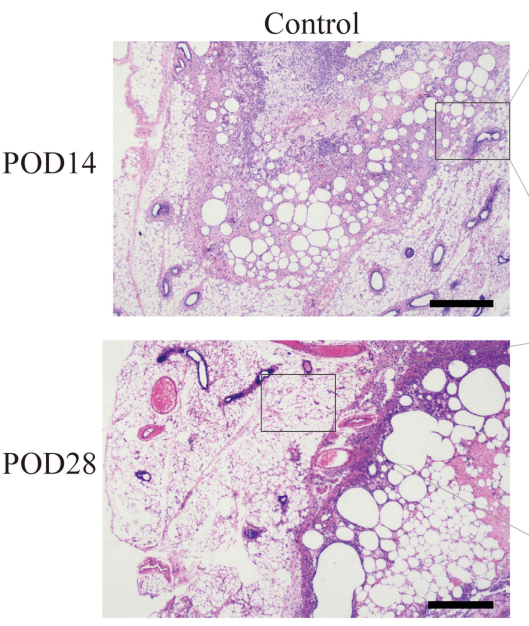

B

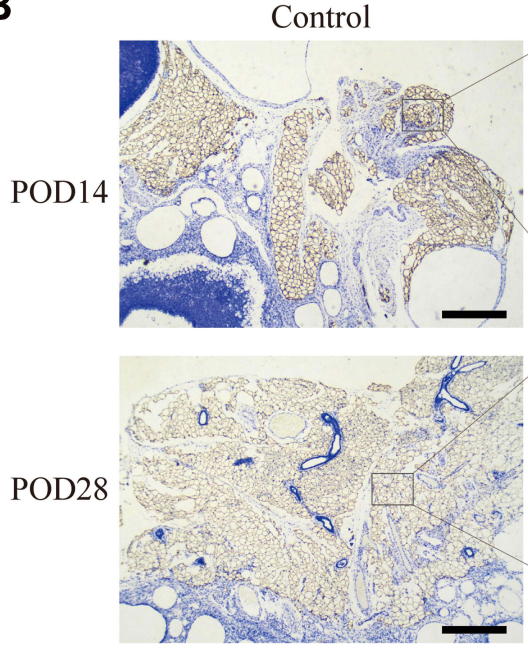

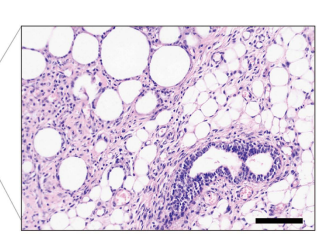
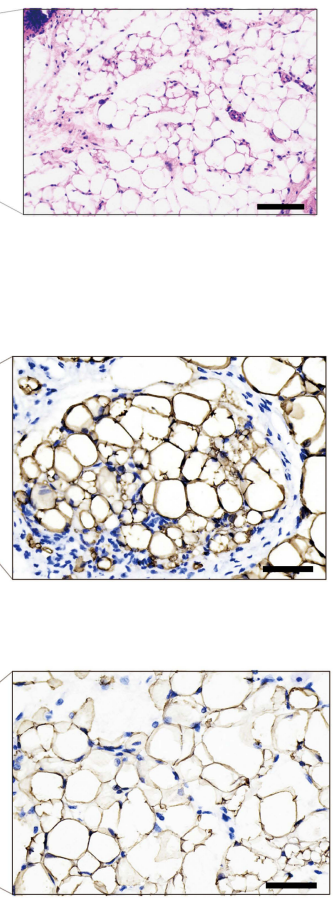
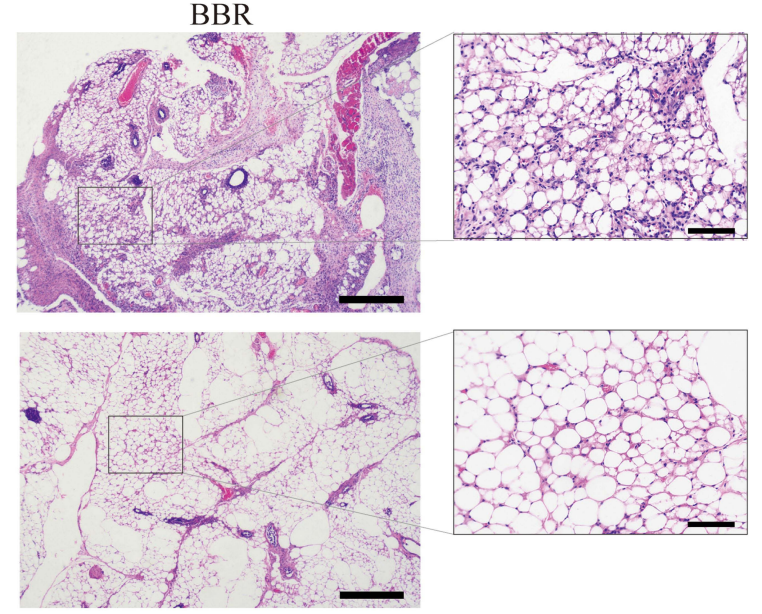

BBR
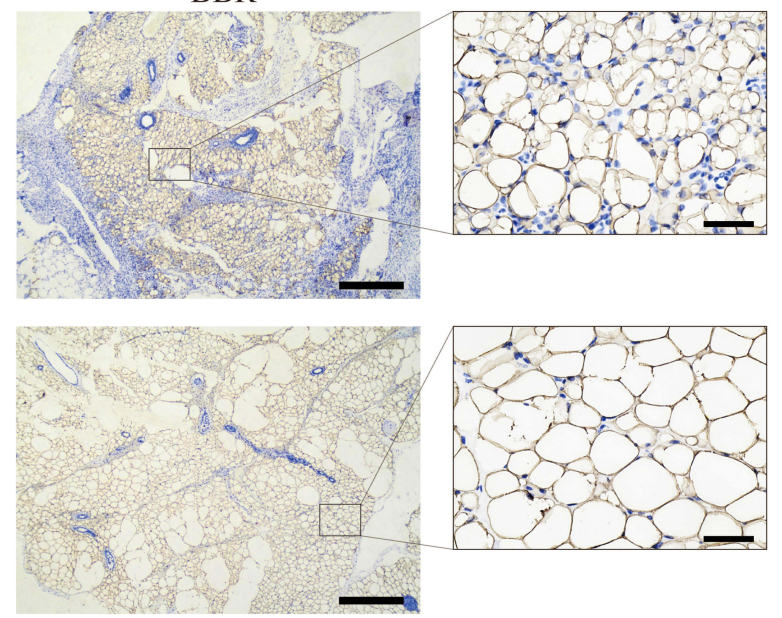

Figure 7 The pathological and histological test. (A) Hematoxylin-and-eosin-stained was performed. (HE stains, left $\times 50$, right $\times 200)$. (B) Perilipin Immunohistochemical analysis to evaluate the survival rate of adipocytes. (IHC, left $\times 50$, right $\times 400)$. 


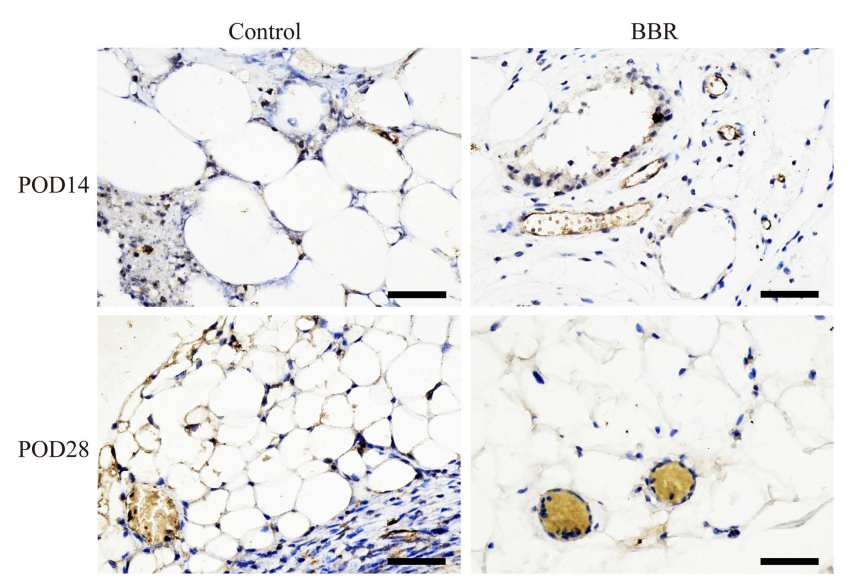

Figure 8 Perilipin Immunohistochemical analysis to assess angiogenesis. (IHC, $\times 400)$.

The results showed that BBR could alleviate the inflammatory cell infiltration, fibrosis level and increase the survival rate of fat grafting, as well as promote angiogenesis. Based on our data, BBR seems to be considered safe and effective for clinical applications. It is reasonable to speculate that BBR can improve the ADSCs survival rate and propose a new strategy to solve the problem of fat survival. In follow-up studies, we need more clinical data and experiments to investigate the mechanism and confirm the clinical utility of BBR before it can be used in this setting.

\section{Conclusion}

Current research has shown that HY/SD conditions induce apoptosis and autophagy of ADSCs. Apoptosis is affected by autophagy. BBR can protect ADSCs from nutritional deficiency through AMPK-mTor pathway, meanwhile, increasing the survival rate of fat and promoting angiogenesis in vivo. These data support that BBR may be a promising agent for improving the survival rate of ADSCs during cell transplantation.

\section{Acknowledgments}

Thanks to all the contributors and participants.

\section{Funding}

This work was supported by the National Natural Science of China (Grant 81471796) and Heilongjiang Province Science Foundation for Excellent Youth Scholars (Grant JC2017019).

\section{Disclosure}

The authors declare that they have no competing interests.

\section{References}

1. Fu X, Wang $\mathrm{H}, \mathrm{Hu}$ P. Stem cell activation in skeletal muscle regeneration. Cell Mol Life Sci. 2015;72(9):1663-1677. doi:10.1007/s00018-014-1819-5

2. Joanisse S, Nederveen JP, Snijders T, McKay BR, Parise G. Skeletal muscle regeneration, repair and remodelling in aging: the importance of muscle stem cells and vascularization. Gerontology. 2017;63 (1):91-100. doi:10.1159/000450922

3. Strong AL, Cederna PS, Rubin JP, Coleman SR, Levi B. The current state of fat grafting: a review of harvesting, processing, and injection techniques. Plast Reconstr Surg. 2015;136(4):897-912. doi:10.1097/ PRS.0000000000001590

4. Gal S, Xue Y, Pu LLQ. What do we know now about autologous fat grafting? Ann Plast Surg. 2019;83(4SSuppl 1):S17-S20. doi:10.1097/ SAP.0000000000002097

5. Yang F, Du L, Song G, et al. Rapamycin and 3-methyladenine influence the apoptosis, senescence, and adipogenesis of human adipose-derived stem cells by promoting and inhibiting autophagy: an in vitro and in vivo study. Aesthetic Plast Surg. 2021;45 (3):1294-1309. doi:10.1007/s00266-020-02101-6

6. D'Arcy MS. Cell death: a review of the major forms of apoptosis, necrosis and autophagy. Cell Biol Int. 2019;43(6):582-592. doi:10.1002/cbin. 11137

7. Thorburn A. Apoptosis and autophagy: regulatory connections between two supposedly different processes. Apoptosis. 2008;13 (1):1-9. doi:10.1007/s10495-007-0154-9

8. Mizushima N. Autophagy: process and function. Genes Dev. 2007;21 (22):2861-2873. doi:10.1101/gad.1599207

9. Hardie DG. AMP-activated/SNF1 protein kinases: conserved guardians of cellular energy. Nat Rev Mol Cell Biol. 2007;8(10):774-785. doi: $10.1038 / \mathrm{nrm} 2249$

10. Villanueva-Paz M, Cotan D, Garrido-Maraver J, et al. AMPK regulation of cell growth, apoptosis, autophagy, and bioenergetics. Exp Suppl. 2016;107:45-71. doi:10.1007/978-3-319-43589-3_3

11. Elmore S. Apoptosis: a review of programmed cell death. Toxicol Pathol. 2007;35(4):495-516. doi:10.1080/ 01926230701320337

12. Meynet O, Zunino B, Happo L, et al. Caloric restriction modulates Mcl-1 expression and sensitizes lymphomas to $\mathrm{BH} 3$ mimetic in mice. Blood. 2013;122(14):2402-2411. doi:10.1182/blood-201301-478651

13. Faivre S, Kroemer G, Raymond E. Current development of mTOR inhibitors as anticancer agents. Nat Rev Drug Discov. 2006;5 (8):671-688. doi: $10.1038 / \mathrm{nrd} 2062$ 
14. Wang WZ, Fang XH, Williams SJ, et al. Analysis for apoptosis and necrosis on adipocytes, stromal vascular fraction, and adipose-derived stem cells in human lipoaspirates after liposuction. Plast Reconstr Surg. 2013;131(1):77e-85e. doi:10.1097/PRS.0b013e3182729ff7

15. Medina MA 3rd, Nguyen JT, Kirkham JC, et al. Polymer therapy: a novel treatment to improve fat graft viability. Plast Reconstr Surg. 2011;127(6):2270-2282. doi:10.1097/PRS.0b013e3182139fc1

16. Inhibition of chemical carcinogenesis by berberine in rats and mice. pdf.

17. Sun Y, Wang W, Tong Y. Berberine inhibits proliferative ability of breast cancer cells by reducing metadherin. Med Sci Monit. 2019;25:9058-9066. doi:10.12659/MSM.914486

18. Habtemariam S. Berberine pharmacology and the gut microbiota: a hidden therapeutic link. Pharmacol Res. 2020;155:104722. doi:10.1016/j.phrs.2020.104722

19. Cho BJ, Im EK, Kwon JH, et al. Berberine inhibits the production of lysophosphatidylcholine-induced reactive oxygen species and the ERK1/2 pathway in vascular smooth muscle cells. Mol Cells. 2005;20(3):429-434.

20. Liu W, Liu P, Tao S, et al. Berberine inhibits aldose reductase and oxidative stress in rat mesangial cells cultured under high glucose. Arch Biochem Biophys. 2008;475(2):128-134. doi:10.1016/j. abb.2008.04.022

21. Oh DS, Cheon YW, Jeon YR, Lew DH. Activated platelet-rich plasma improves fat graft survival in nude mice: a pilot study. Dermatol Surg. 2011;37(5):619-625. doi:10.1111/j.1524-4725.2011.01953.x

22. Guney K, Tatar S, Ozel B, et al. The effect of minocycline on fat graft survival and apoptotic pathway. Facial Plast Surg. 2019;35 (1):96-102. doi:10.1055/s-0039-1677709

23. Fathi E, Farahzadi R, Charoudeh HN. L-carnitine contributes to enhancement of neurogenesis from mesenchymal stem cells through Wnt/beta-catenin and PKA pathway. Exp Biol Med (Maywood). 2017;242(5):482-486. doi:10.1177/1535370216685432

24. Li Q, Yin Y, Zheng Y, Chen F, Jin P. Inhibition of autophagy promoted high glucose/ROS-mediated apoptosis in ADSCs. Stem Cell Res Ther. 2018;9(1):289. doi:10.1186/s13287-018-1029-4

25. Li M, Zhang M, Zhang ZL, et al. Induction of apoptosis by berberine in hepatocellular carcinoma HepG2 cells via downregulation of NF-kappaB. Oncol Res. 2017;25(2):233-239. doi:10.3727/ 096504016X14742891049073

26. Wang J, $\mathrm{Wu} \mathrm{H}$, Zhou $\mathrm{Y}$, et al. HIF-1alpha inhibits mitochondria-mediated apoptosis and improves the survival of human adipose-derived stem cells in ischemic microenvironments. J Plast Reconstr Aesthet Surg. 2021;74(8):1908-1918. doi:10.1016/j. bjps.2020.11.041

27. Zhang X, Guan T, Yang B, Chi Z, Wan Q, Gu HF. Protective effect of berberine on high glucose and hypoxia-induced apoptosis via the modulation of HIF-1alpha in renal tubular epithelial cells. Am $J$ Transl Res. 2019;11(2):669-682.

28. Fathi E, Farahzadi R, Valipour B. Alginate/gelatin encapsulation promotes NK cells differentiation potential of bone marrow resident C-kit(+) hematopoietic stem cells. Int $J$ Biol Macromol. 2021;177:317-327. doi:10.1016/j.ijbiomac.2021.02.131

29. Fathi E, Farahzadi R, Vietor I, Javanmardi S. Cardiac differentiation of bone-marrow-resident c-kit $(+)$ stem cells by L-carnitine increases through secretion of VEGF, IL6, IGF-1, and TGF- beta as clinical agents in cardiac regeneration. $J$ Biosci. 2020;45:45.

30. Coleman SR. Structural fat grafts: the ideal filler? Clin Plast Surg. 2001;28(1):111-119. doi:10.1016/S0094-1298(20)32343-9

31. Coleman SR. Structural fat grafting: more than a permanent filler. Plast Reconstr Surg. 2006;118(3Suppl):108S-120S. doi:10.1097/01. prs.0000234610.81672.e7

32. Pu LLQ, Coleman SR, Cui X, Ferguson REH Jr, Vasconez HC. Autologous fat grafts harvested and refined by the Coleman technique: a comparative study. Plast Reconstr Surg. 2008;122(3):932-937. doi:10.1097/PRS.0b013e3181811ff0
33. Miura Y. [Basics and clinical application of human mesenchymal stromal/stem cells]. Rinsho Ketsueki. 2015;56(10):2195-2204. Japanese. doi:10.11406/rinketsu.56.2195

34. Jamshaid F, Dai J, Yang LX. New development of novel berberine derivatives against bacteria. Mini Rev Med Chem. 2020;20 (8):716-724. doi:10.2174/1389557520666200103115124

35. Jahagirdar D, Gore CR, Patel H, Maria K, Tandon I, Sharma NK. Induction of apoptotic death and cell cycle arrest in HeLa cells by extracellular factors of breast cancer cells. Asian Pac J Cancer Prev. 2018;19(12):3307-3316. doi:10.31557/APJCP.2018.19.12.3307

36. Okubo S, Uto T, Goto A, et al. Berberine induces apoptotic cell death via activation of Caspase-3 and -8 in HL-60 human leukemia cells: nuclear localization and structure-activity relationships. Am J Chin Med. 2017;45(7):1497-1511. doi:10.1142/S0192415X17500811

37. Jin $\mathrm{H}$, Jin $\mathrm{X}$, Cao B, Wang W. Berberine affects osteosarcoma via downregulating the caspase-1/IL-1beta signaling axis. Oncol Rep. 2017;37(2):729-736. doi:10.3892/or.2016.5327

38. Wang N, Feng Y, Zhu M, et al. Berberine induces autophagic cell death and mitochondrial apoptosis in liver cancer cells: the cellular mechanism. J Cell Biochem. 2010;111(6):1426-1436. doi:10.1002/ jcb.22869

39. Zhang D, Ke L, Ni Z, et al. Berberine containing quadruple therapy for initial Helicobacter pylori eradication: an open-label randomized Phase IV trial. Medicine (Baltimore). 2017;96(32):e7697. doi:10.1097/MD.0000000000007697

40. Yu L, Li Q, Yu B, et al. berberine attenuates myocardial ischemia/ reperfusion injury by reducing oxidative stress and inflammation response: role of silent information Regulator 1. Oxid Med Cell Longev. 2016;2016:1689602. doi:10.1155/2016/1689602

41. Cicero AFG, Fogacci F, Colletti A. Food and plant bioactives for reducing cardiometabolic disease risk: an evidence based approach. Food Funct. 2017;8(6):2076-2088. doi:10.1039/C7FO00178A

42. Wu L, Xia M, Duan Y, et al. Berberine promotes the recruitment and activation of brown adipose tissue in mice and humans. Cell Death Dis. 2019;10(6):468. doi:10.1038/s41419-019-1706-y

43. Zhang Z, Zhang H, Li B, et al. Berberine activates thermogenesis in white and brown adipose tissue. Nat Commun. 2014;5:5493. doi:10.1038/ncomms6493

44. Kerr JF. History of the events leading to the formulation of the apoptosis concept. Toxicology. 2002;181-182:471-474. doi:10.1016/ S0300-483X(02)00457-2

45. Cao YJ, Shibata T, Rainov NG. Hypoxia-inducible transgene expression in differentiated human NT2N neurons-a cell culture model for gene therapy of postischemic neuronal loss. Gene Ther. 2001;8 (17):1357-1362. doi:10.1038/sj.gt.3301536

46. Wang G, Hazra TK, Mitra S, Lee HM, Englander EW. Mitochondrial DNA damage and a hypoxic response are induced by $\mathrm{CoCl}(2)$ in rat neuronal PC12 cells. Nucleic Acids Res. 2000;28(10):2135-2140. doi:10.1093/nar/28.10.2135

47. Robey TE, Saiget MK, Reinecke H, Murry CE. Systems approaches to preventing transplanted cell death in cardiac repair. $J$ Mol Cell Cardiol. 2008;45(4):567-581. doi:10.1016/j.yjmcc.2008.03.009

48. Yu L, Wan F, Dutta S, et al. Autophagic programmed cell death by selective catalase degradation. Proc Natl Acad Sci U S A. 2006;103 (13):4952-4957. doi:10.1073/pnas.0511288103

49. Hardie DG, Schaffer BE, Brunet A. AMPK: an energy-sensing pathway with multiple inputs and outputs. Trends Cell Biol. 2016;26 (3): 190-201. doi:10.1016/j.tcb.2015.10.013

50. Li Y, Chen Y. AMPK and autophagy. Adv Exp Med Biol. 2019;1206:85-108.

51. Pu LL. Mechanisms of fat graft survival. Ann Plast Surg. 2016;77 (Suppl 1):S84-6. doi:10.1097/SAP.0000000000000730

52. Eto H, Kato H, Suga H, et al. The fate of adipocytes after nonvascularized fat grafting: evidence of early death and replacement of adipocytes. Plast Reconstr Surg. 2012;129(5):1081-1092. doi:10.1097/PRS.0b013e31824a2b19 
53. Tonnard P, Verpaele A, Peeters G, Hamdi M, Cornelissen M, Declercq H. Nanofat grafting: basic research and clinical applications. Plast Reconstr Surg. 2013;132(4):1017-1026. doi:10.1097/PRS.0b013e31829fe1b0
54. Ghorbani A, Baradaran Rahimi V, Sadeghnia HR, Hosseini A. Effect of berberine on the viability of adipose tissue-derived mesenchymal stem cells in nutrients deficient condition. Nat Prod Res. 2018;32 (5):592-595. doi:10.1080/14786419.2017.1324965

\section{Publish your work in this journal}

Drug Design, Development and Therapy is an international, peerreviewed open-access journal that spans the spectrum of drug design and development through to clinical applications. Clinical outcomes, patient safety, and programs for the development and effective, safe, and sustained use of medicines are a feature of the journal, which has also been accepted for indexing on PubMed Central. The manuscript management system is completely online and includes a very quick and fair peer-review system, which is all easy to use. Visit http://www. dovepress.com/testimonials.php to read real quotes from published authors.

Submit your manuscript here: https://www.dovepress.com/drug-design-development-and-therapy-journal 